\title{
A Cross-National Study of Cognitive Styles and Cultural Attitudes of $\mathrm{HCl}$ Students
}

\author{
Ann Austin, Mario Michaelides, Jose Abdelnour-Nocera, Sunila Modi \\ Centre for Internationalisation and Usability \\ University of West London \\ St Marys Rd, Ealing \\ London, W5 5RF \\ \{ann.austin; mario.michaelides; jose.abdelnour-nocera; sunila.modi\}@uwl.ac.uk
}

\begin{abstract}
The discipline of human-computer interaction has become a subject taught across universities around the world, outside of the cultures where it originated. However, the intercultural implication of its assimilation into the syllabus of courses offered by universities around the world remains under-researched. The purpose of this ongoing research project is to provide insights for these implications in terms of the student and teacher experience of $\mathrm{HCl}$. In order to develop intercultural awareness of these questions universities from UK, India, Namibia, Mexico and China are collaborating in a multiple case study involving students and lecturers engaged in a common and evaluation and design tasks. Findings will then be used to propose an international $\mathrm{HCl}$ curriculum more supportive of local perspectives. This paper describes the initial steps of this study and some preliminary findings from Namibia, India, China and Mexico about cognitive styles and cultural attitudes.
\end{abstract}

HCl Education, Culture, Cognitive Styles, Cultural Attitudes, $\mathrm{HCl}$ Curriculum.

\section{INTRODUCTION}

Human-Computer Interaction $(\mathrm{HCl})$ is a wellestablished and important subject in computing, technology and design in universities across the world. $\mathrm{HCl}$ is taught in order to explore, understand and aid in improving the usability and user experience of interactive systems and products. Though similar methodologies and frameworks are taught in this subject, little is known of the student experience and how local perspectives have influenced their content and approach to teaching. Therefore, a current challenge for this discipline is making visible the possible tensions created between local cultures and the assumptions, priorities and values embedded in $\mathrm{HCl}$ concepts and methods mainly developed under particular paradigms.

This project proposes to explore how $\mathrm{HCl}$ is socially represented, taught and experienced in different institutions spanning four continents in China, Namibia, India, Mexico and the United Kingdom. We hope to provide insights on the nature of $\mathrm{HCl}$ education as an intercultural encounter and the opportunities this can bring to locally validate, question and enrich some of its key concepts and methods. Including these insights into an international $\mathrm{HCl}$ curriculum will form designers better prepared to support intercultural collaboration. This paper describes the initial steps of this study and some preliminary findings from
Namibia, India, China and Mexico about cognitive styles and cultural attitudes.

\section{CULTURE AND COGNITION}

Smith et al. (2007) suggest that western $\mathrm{HCl}$ tools and techniques might not be effective in developing countries and that some degree of localisation or adaptation are required. An objective of this project is to look into this in a $\mathrm{HCl}$ education context, and to make sense of variations, convergences and emergences from a student centred perspective. In this section we describe the main cultural theories underpinning this objective.

Researchers in the fields of both culture and cognitive styles have identified a correlation between cultural characteristics and the holistic or intuitive versus analytical dimensions of cognitive style (Nisbett \& Norenzayan 2002; Hayes \& Allinson 1988).

Nisbett \& Norenzayan (2002) explored the relationship between culture and cognition by looking at cultural differences between East Asians and people from the Western world. They discussed how an inclination towards holistic or analytic reasoning is influenced by cultural identities. Nisbett differentiates between holistic and analytic reasoning, defining holistic thought as 'an orientation to the context or field as a whole' and analytic thought as 'detachment of the object 
from its context' (Nisbett \& Norenzayan 2002, p.19).

Hayes and Allinson tested the hypothesis that culture would account for differences in learning style in a study involving managers from East Africa, India and the United Kingdom. Using Hofstede's (1991) four national culture dimensions and Honey and Mumford's Learning Style models, Hayes and Allinson identified two dimensions of learning style, Analysis and Action (Hayes \& Allinson 1988). Further work in this area resulted in Allinson and Hayes' Cognitive Style Index (CSI) designed to test whether individuals tends more towards an intuitivist (right brain dominant) or analyst (left brain dominant) approach.

\section{METHODOLOGICAL STRATEGY}

The case study in each country includes a visit to a university where a group of around $15-20$ undergraduate $\mathrm{HCl}$ students will be asked to engage in a workshop, which includes evaluation and design tasks for a science education portal. The activity given to students will act as a cultural probe (Gaver et al. 1999) as it contains elements with different cultural affordances, e.g. heuristic evaluation as stimulating analytic thinking and prototype sketching as stimulating holistic thinking. The visit will also include meetings and interviews with lecturers and staff in charge of curriculum design. In addition, documents and course materials produced by the university will be analyzed.

Quantitative data on culture for each student group will be collected using Hofstede's VSM instrument, and Hayes and Allinson's CSI survey will be used to situate each student in an intuitive-holistic scale. We acknowledge the limitations of Hofstede's model on national culture (McSweeney 2002) and are very careful not to make stereotypical interpretations or generalizations from the data collected. We are not expecting students to match the national culture scores 'predictions' for their country. The fact that they are in different countries make them more likely to be contrasting. However, we still believe that it will be useful to find out the mean scores for each group on each cultural dimension, e.g. power distance, masculinity and collectivism, to enrich our comparative analysis of quantitative and qualitative data. Qualitative data will be analyzed for manifestations of national culture dimensions (Hofstede, 1991), cognitive styles (Nisbett \& Miyamoto, 2005) and high and low context cultures (Hall, 1993). While these different cultural models give us a top-down framework for analysis, a bottom up analysis of this data will also be developed. In this case the aim will be to uncover cultural patterns, themes and dimensions exclusively emerging from the $\mathrm{HCl}$ education domain.

\section{WORKSHOPS}

So far, workshops have been conducted at the Polytechnic of Namibia, the Instituto Tecnológico Autónomo de México (ITAM), the Indian Institute of Technology Guwahati (IITG) and the Dalian Maritime University in China (DMU). All 4 institutions are well respected within their country. Within these institutions, $\mathrm{HCl}$ was a core subject in Namibia, an option in Mexico, embedded within the whole curriculum in India and a core subject in the last semesters in DMU's Computer Science course.

The workshop involved the student in evaluating a learning node in the SEED science portal (www.planetseed.com). The target audience of this portal is schoolchildren aged between 10 and 18, and the $\mathrm{HCl}$ students were required to evaluate the node in this context. The SEED portal supports a number of different language options, allowing students who do not have English as their first language to use their preferred language option and concentrate on the task in question.

These activities included a heuristic evaluation of a learning task in the portal to determine whether the design satisfied certain predefined characteristics, which requires an analytical approach. In addition, the students were asked to analyse and comment on the case study scenario. The next tasks required a more holistic and intuitive approach: the students were required to develop the persona of both a student and her teacher, and to redesign the portal in view of their findings from the heuristic evaluation. The final tasks related to analysing their redesign in relation to standard $\mathrm{HCl}$ theory and concepts.

\section{PRELIMINARY FINDINGS}

In this section we report some of our findings in relation to the cognitive styles and culture surveys with the student groups in these three countries.

$\mathrm{HCl}$ practitioners act as an interface between the developer and the users during the development of computer application or website. In terms of cognitive styles this means they need analytical skills to understand the functionality of the website or application, but at the same time, they need to be able to see the 'whole picture' and put themselves in the shoes of the user. Some $\mathrm{HCl}$ evaluation techniques such as heuristic evaluations require an analytical approach. Others, such as the production of a persona need a more intuitive approach. In addition, whilst the developer may be 
more concerned with the functionality of the application, the $\mathrm{HCl}$ practitioner also needs to balance the need for the interface to be user friendly, and the layout, appearance and aesthetics of the interface will contribute to this. Given this, we would expect the most typical styles to be found in successful $\mathrm{HCl}$ students to be more balanced, ranging from quasi intuitive and intuitive to quasi analytic.

With the above expectation, the CSI was administered to a total of $89 \mathrm{HCl}$ students in Namibia $(n=21)$, Mexico $(n=25)$, India $(n=23)$ and China $(n=20)$. Of these, 9 surveys had missing responses and were disregarded. Of these remaining 80 students, $79 \%$ were found to fall in the category of Quasi Intuitive $(n=24)$, Adaptive $(n=20)$ and Quasi Analyst $(n=20)$. The remaining $21 \%$ were split between Intuitive $(n=6)$ and Analyst $(n=11)$. However, what is particularly interesting is the difference between the 3 cohorts. Namibia, Mexico and China have $78 \%, 73 \%$ and $78 \%$ respectively falling in the categories of quasiintuitive, adaptive and quasi analyst; however, in the case of the Indian students, $95 \%$ fell into this range.

One possible reason for the difference in profile could be due to the unique nature of the programme at the IITG. The IITG has both a Department of Computer Science and Engineering and a Department of Design, and the students who took part in these workshops were Design students. Cohorts from Namibia and Mexico originate in engineering faculties. In the case of ITAM, a small proportion of students were enrolled in financial engineering courses, which might explain the lowest percentage. DMU students are all enrolled in a computer science and technology BSc and showed the highest percentage on analytic profiles in case studies. This correlates with the fact that their student packs were the most detailed of the different country groups.

Cloninger (2000) differentiates between usability (the masculine, the left side of the brain, rational, and logical action) and design (the feminine, the right side of the brain, emotional, and intuitive action), and with these particular cohorts we would expect to see both dimensions represented, which goes some way to explaining the unusual CSI profile where $95 \%$ of Indian students demonstrate styles around 'adaptive' middle point. After all, they are scientists with an aptitude for design.

The VSM data gave us interesting findings in terms of cultural dimensions for the student groups we studied. We do not claim in any way the scores are a reflection on national culture, but mainly use the scores obtained as top-level indicators of students' attitudinal trends in particular dimensions such as power distance and collectivism. The groups of students who completed the survey were nationals of the same country, except in Namibia where we had two Angolans and one South African.

For the cohort in the Polytechnic of Namibia $(\mathrm{N}=21)$, the mean scores for the VSM94 survey indicate the group is individualistic with very low power distance. This is in contrast with Hofstede's scores for most of sub-Saharan Africa indicating collectivistic societies with a tendency to a high power distance. They seem to be consistent with South Africa's scores but the latter represent respondents with British or Dutch background, whereas the Namibian cohort is fundamentally African. This might be a reflection of the culture of Namibian universities founded and developed by Europeans

For students in ITAM (Mexico) (N=24), (IITG) $(\mathrm{N}=27)$ and China $(\mathrm{N}=31)$, VSM 08 was used. The decision to move to a more recent instrument was based on the fact that it offered more flexibility in establishing baseline scores for comparison of the groups. This means, however, we cannot make a direct score comparison with the students in Namibia. Figure 1 presents the results for both countries and there are some contrasts worth noting.

The Power Distance (PDI) dimension was evident particularly in the relationship between the students and their professor or ourselves as researchers. The behaviour of students in China, India and Mexico during the workshops reflects the difference indicated by the survey: Chinese students were the most complying ones in relation to instructions given by us and followed instructions without any question (PDI=85), Indian (PDI=62) students were more respectful and distant while Mexican (PDI=47) students were slightly more relaxed. This has a direct effect on the reflective learning process required in concepts and methods in $\mathrm{HCl}$ where the student is required to approach users and stakeholders with different levels of authority.

Original Hofstede's scores for Mexico and India indicate that the former is less individualistic than the latter. In our survey we have found the opposite (IDV: Mexico=89; India=69). This can be a reflection of the university culture in ITAM, where a lot of emphasis on individual success is evident in terms of financial awards in the form of fee waivers for the best performing students. While attempting the tasks, Mexican students displayed more independence and less interaction between peers than in India. Chinese students were clearly the more collectivist ones in terms of their group behaviour during the exercise $(I D V=60)$. They would be very careful of individual comments while 
in the group and were attentive of keeping the same pace as that of the group.

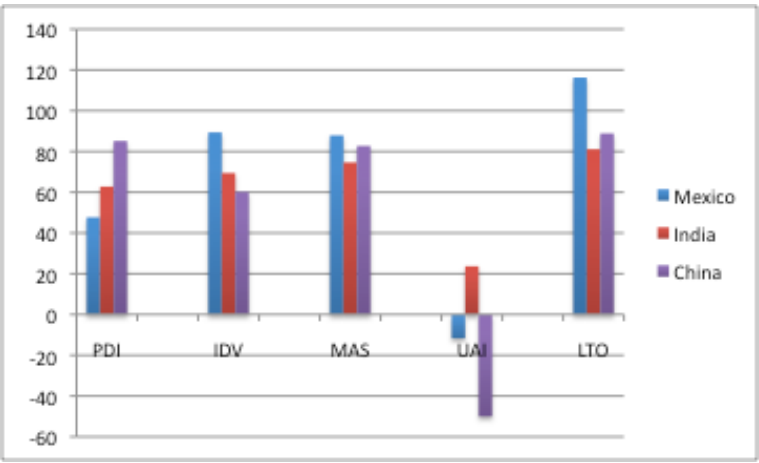

Figure 1 - Cultural Dimensions India and Mexico Cohorts

Uncertainty avoidance was particularly evident in the difference in the style of teaching between Mexico (UAI= -11) and India (UAI= 23). During the workshop in IITG, certain elements of the theory were revisited prior to the activity taken place. These were delivered by us in the same style that they are delivered to UK students which was to explain the theory and explain the task in relation to the theory. Feedback from the faculty staff indicated that this would not have been sufficiently structured for Indian students, who would expect a framework of theory, some examples, followed by a worked case study example. In contrast, Students in ITAM and DMU completed the activity independently at their own pace after a common induction and required minimum assistance to get them started. Low UAI score for Chinese students in this study (UAI=-50) reflects also the same independence as ITAM students.

\section{CONCLUSIONS}

This project aims to find opportunities and challenges for the dissemination and enrichment of this discipline through eliciting and assessing the importance of local, disciplinary, national and $\mathrm{HCl}$ cultures. It does so by exploring the context, performance and views of stakeholders involved in learning and teaching. The preliminary findings presented here make visible the values and assumptions shaping the experience of $\mathrm{HCl}$ education.

While Hofstede's dimensions have been heavily criticised as valid indicators of national culture, we believe that their use at group level can introduce $\mathrm{HCl}$ educators to an initial reflection on the implications for students of the values, relations and interactions scripted in the content and delivery of $\mathrm{HCl}$ concepts and methods. In addition, our initial analysis of cognitive styles indicates an interesting tension between $\mathrm{HCl}$ as design subject and as an engineering subject. This leads us to another observation: the entry exams for some schools like ITAM or DMU will filter a particular type of student who will tend to be more of an engineer than a designer, therefore reducing the number of potentially 'ideal' $\mathrm{HCl}$ professionals.

Once the qualitative phase of the analysis of student work begins, we hope to obtain richer insights that connect their outputs with the cultural and cognitive profiles presented in this paper.

This project provides a unique opportunity to systematically compare and analyse data obtained from four continents. We are aware that it stands in different epistemological positions as it looks, on one hand, at performance and, on the other hand, at meanings used to represent and experience $\mathrm{HCl}$. However, we see this as an opportunity for triangulation, co-validation and enhanced understanding of $\mathrm{HCl}$ education in a multicultural context.

\section{REFERENCES}

Cloninger, C., 2000. Usability Experts are from Mars, Graphic Designers are from Venus [online]. A List Apart, No.74. Available at <http://www.alistapart.com/articles/marsvenus> [Accessed 10 May 2012].

Gaver, B., Dunne, T. \& Pacenti, E., 1999. Cultural Probes. ACM Interactions, 6(1), pp.21-29.

Hall, E.T., 1993. An Anthropology of Everyday Life : an Autobiography, New York: Anchor Books.

Hayes, J. \& Allinson, C.W., 1988. Cultural Differences in the Learning Styles of Managers. Management International Review, pp.75-80.

Hofstede, G., 1991. Cultures and Organizations: Software of the Mind., Berkshire,UK: Mc Graw-Hill.

McSweeney, B., 2002. Hofstede's model of National Cultural Differences and their Consequences: A Triumph of Faith - A Failure of Analysis. Human Relations, 55(1), pp.89-118.

Nisbett, R.E. \& Miyamoto, Y., 2005. The Influence of Culture: Holistic Versus Analytic Perception. Trends in Cognitive Sciences, 9(10), pp.467-473.

Nisbett, R. E. \& Norenzayan, A., 2002. Culture and cognition. Stevens' Handbook of Experimental Psychology.

Smith, A., Joshi, A., Liu, Z., Bannon, L., Gulliksen, J. and Baranauskas, C., 2007. Embedding $\mathrm{HCl}$ in Developing Countries: Localizing Content, Institutionalizing Education and Practice. 